\title{
ERCC1 protein, mRNA expression and T19007C polymorphism as prognostic markers in head and neck squamous cell carcinoma patients treated with surgery and adjuvant cisplatin-based chemoradiation
}

\author{
GILBERTO DE CASTRO Jr ${ }^{1}$, FATIMA SOLANGE PASINI ${ }^{2}$, \\ SHEILA APARECIDA COELHO SIQUEIRA ${ }^{3}$, ALBERTO ROSSETTI FERRAZ ${ }^{4}$, ROSANGELA CORREA VILLAR ${ }^{5}$, \\ IGOR MOYSÉS LONGO SNITCOVSKY ${ }^{2}$ and MIRIAM HATSUE HONDA FEDERICO ${ }^{2}$
}

\begin{abstract}
${ }^{1}$ Clinical Oncology, Instituto do Câncer do Estado de São Paulo, Av. Dr. Arnaldo 251, São Paulo SP 01246000;
${ }^{2}$ Disciplina de Oncologia, Laboratório de Investigação Médica LIM-24, Faculdade de Medicina da Universidade de São Paulo, Av. Dr. Arnaldo 455, São Paulo SP 01246903; ${ }^{3}$ Pathology Division, Hospital das Clínicas da Faculdade de Medicina da Universidade de São Paulo, Av. Dr. Enéas de Carvalho Aguiar 155, São Paulo; ${ }^{4}$ Head and Neck Surgery Service, Hospital das Clínicas da Faculdade de Medicina da Universidade de São Paulo, Av. Dr. Enéas de Carvalho Aguiar 255, São Paulo SP 05403900; ${ }^{5}$ Radiation Oncology Service, Instituto de Radiologia-InRad, Hospital das Clínicas da Faculdade de Medicina da Universidade de São Paulo, Av. Dr. Enéas de Carvalho Aguiar 255, São Paulo SP 05403001, Brazil
\end{abstract}

Received October 13, 2010; Accepted November 29, 2010

DOI: $10.3892 /$ or.2011.1133

\begin{abstract}
Adjuvant cisplatin-based chemoradiation improves survival in HNSCC patients presenting with risk features. ERCC1 (excision repair cross-complementation group 1) is associated with resistance to chemo- and radiation therapy and may have a prognostic value in HNSCC patients. Here we studied ERCC1 expression and the polymorphism T19007C as prognostic markers in these patients. This is a retrospective and translational analysis, where ERCC1 protein expression was evaluated by immunohistochemistry, using an H-score, and mRNA expression was determined by RT-PCR. T19007C genotypes were detected by PCRRFLP carried out using DNA template extracted from normal lymph nodes. A high $\mathrm{H}$-score was seen in 32 patients (54\%), who presented better 5-year overall survival (5-y OS: $50 \%$ vs. $18 \%$, HR $0.43, \mathrm{p}=0.026)$. Fifteen out of 45 patients $(33 \%)$, with high mRNA expression, presented better 5-year overall survival (OS) ( $86 \%$ vs. $30 \%$, HR $0.26, p=0.052)$. No OS difference was detected among T19007C genotypes. High $\mathrm{H}$-score and mRNA expression remained significant as
\end{abstract}

Correspondence to: Dr Gilberto de Castro Jr, Instituto do Câncer do Estado de São Paulo, Clinical Oncology, Av. Dr. Arnaldo 251, 5th floor, São Paulo, SP 01246-000, Brazil

E-mail: gilberto.castro@usp.br

Key words: excision repair cross-complementation group 1, head and neck squamous cell carcinoma, chemoradiation, cisplatin, single nucleotide polymorphisms favorable prognostic factors in a multivariate analysis. Collectively, our results suggest that high ERCC1 expression seems to be associated with better OS rates in HNSCC patients submitted to adjuvant cisplatin-based chemoradiation.

\section{Introduction}

Head and neck cancer accounts for around 645,000 new cases each year, worldwide, $75 \%$ of them with stage III-IV disease, causing more than 350,000 deaths yearly (1). Adjuvant cisplatin-based concurrent chemoradiation improves progression-free survival in patients diagnosed with head and neck squamous cell carcinoma (HNSCC) presenting with risk features, submitted to surgery with curative intent, and OS gains are seen in some subgroups (2-5). A hurdle in the interpretation of these trials is patient heterogeneity, in spite of attempts to control for prognostic factors.

Cisplatin cytotoxicity is based on the formation of interstrand and intrastrand cross-links, caused by adducts in the DNA structure, blocking nucleotide replication and transcription. Nucleotide excision repair (NER) is one of the molecular mechanisms involved in DNA repair and mediates cell sensitivity to cisplatin. It comprised more than 30 distinct proteins that recognize DNA damage, incise the lesion, and resynthesize and ligate the repair patch (6). The excision repair cross-complementation group 1 (ERCC1) protein plays a rate-limiting role in the NER pathway: it forms a complex with Xeroderma Pigmentosum Complementation Group F and this complex is involved in the $5^{\prime}$ excision of the damaged DNA (7).

As expected, lower ERCC1 expression, either evaluated as mRNA expression or protein levels, correlates with better outcomes in several cancers after platinum-based therapy, 
including HNSCC, suggesting that ERCCI expression could have a role in predicting sensitivity to cisplatin-based chemotherapy (8-12). In contrast to this effect, a low expression of ERCC1 per se may at the same time be associated with the accumulation of DNA mutations and results in a more aggressive tumor phenotype (13-16). Thus, ERCC1 expression may have itself a dual effect in terms of prognosis. In the HNSCC patients treated by both surgery and adjuvant cisplatin-based chemoradiation, the predominant effect of ERCC1 remains still unclear.

In addition, some single nucleotide polymorphisms (SNPs) of ERCC1 have been described, some of them are thought to be functional. Particularly interesting is the SNP T19007C:rs11615 in codon 118, which has been associated with response rate and/or overall survival in patients diagnosed with colorectal cancer $(17,18)$. In other tumor types, including HNSCC, however, this association was not consistently demonstrated (19-22).

We studied ERCCI expression at protein and mRNA levels and the role of the ERCC1 SNP T19007C as prognostic markers in HNSCC patients presenting with risk features treated with surgery and adjuvant chemoradiation.

\section{Materials and methods}

Patient population. In this retrospective analysis, eligibility requirements were: histologically-proven SCC of oral cavity, oropharynx, hypopharynx, or larynx; patients had to be submitted to radical surgery with curative intent, and considered to be candidates to adjuvant chemoradiation, due to the presence of high- or intermediate-risk factors (extracapsular spread in positive lymph nodes, surgical margins microscopically involved, stage III/IV disease, positive lymph nodes at levels IV or $\mathrm{V}$ in patients with tumors arising from oropharynx or oral cavity, lymphovascular embolisms, perineural infiltration); they had to be treated with at least one cycle of chemotherapy; no distant metastasis; no relapsed disease after surgery; no other malignancy; no other therapy before or after surgery. Adjuvant chemoradiation consisted of 60-70 Gy, conventionally delivered (one daily fraction of $200 \mathrm{cGy}, 5$ times a week), concurrently to cisplatin $100 \mathrm{mg} / \mathrm{m}^{2}$, intravenously, on days 1, 22 and 43. The study protocol was approved by the local institutional ethics committee.

Immunohistochemical analysis for ERCC1. Fifty-nine formalin-fixed, paraffin-embedded tissue blocks were available for immunohistochemical analysis. A standardized immunohistochemistry protocol was used. Briefly, 5- $\mu \mathrm{m}$ thick tissue sections were deparaffinized, rehydrated and slides were soaked in $6 \% \mathrm{H}_{2} \mathrm{O}_{2}, 5$ times, 5 min each. After, they were exposed to citrate buffer $0.01 \mathrm{M}, \mathrm{pH} 6.0$ in a pressure cooker for 2-5 min for antigen retrieval. Tumor sections were then incubated with the murine primary antibody anti-ERCC1 (antibody Ab-2, clone 8F1, NeoMarkers, Fremont, CA, USA) diluted in $1 \%$ albumin/PBS diluents, overnight at $4^{\circ} \mathrm{C}$ in a humid chamber for $18 \mathrm{~h}$. Slides were then incubated with the secondary antibody solution conjugated with a polymer (Novolink, Novocastra, Bannockburn, IL, USA) for $30 \mathrm{~min}$ at $37^{\circ} \mathrm{C}$. The chromogenic substrate diaminobenzidine $60 \mathrm{mg} / 100 \mathrm{ml}$ in PBS and
$\mathrm{H}_{2} \mathrm{O}_{2}$ was then applied to cover the tissue sections for 3-5 min at $37^{\circ} \mathrm{C}$. Slides were counterstained with Mayer's hematoxylin, rinsed with water, and then dehydrated. Positive and negative external controls were used.

Tumor staining was assessed by a trained pathologist (SACS) who had no knowledge of patients' clinical data, and microscopic analysis was done using the $\mathrm{H}$-score as previously described $(8,23)$. ERCC1 tumor (nuclei) staining intensity was graded on a scale of $0-3$, using adjacent non-malignant cells as a reference (intensity grade, 2 ). The percentage of positive tumor cells was evaluated in 1000 tumor cells and a proportion score was attributed: 0 if $0 \%, 0.1$ if $1-9 \%, 0.5$ if $10-49 \%$, and 1.0 if $50 \%$ or more. This proportion score was then multiplied by the staining intensity to obtain a final semiquantitative $\mathrm{H}$-score. The optimal cut-off value for differentiation of patient's categories (high or low expression) was defined by ROC analysis (see below).

Isolation of nucleic acids. Genomic DNA and total RNA were extracted from formalin-fixed, paraffin-embedded tissue blocks of tumor-free lymph nodes and primary tumor, respectively, by using the RecoverAll Total Nucleic Acid Isolation Kit (Ambion, Austin, TX, USA), according to the manufacturer's instructions. For each sample, 3-4 10-20- $\mu \mathrm{m}$ thick block sections were deparaffinized in xylene at $50^{\circ} \mathrm{C}$ for $3 \mathrm{~min}$, and the pellet was washed with ethanol twice. Each sample was submitted to digestion with protease, and for RNA or DNA isolation, samples were incubated with DNase or RNase, respectively. After successive washings, nucleic acids were eluted in nuclease-free water at $95^{\circ} \mathrm{C}$.

Quantitative real-time reverse transcriptase-PCR. As the RNA extracted from formalin-fixed tissues is likely to be degraded, it was planned to analyze small amplicons. RNA integrity was assessed through microfluidic analysis in the Agilent 2100 Bioanalyzer (Agilent Technologies, Waldbronn, Germany) and its concentration was determined by measuring its absorbance at $260 \mathrm{~nm}$ using the NanoDrop 1000 Spectrophotometer (Thermo Scientific, Wilmington, DE, USA). Quantitative real-time reverse transcriptase polymerase chain reaction (qRT-PCR) was used to determine ERCC1 mRNA expression, normalized by using $18 \mathrm{~S}$ fraction of ribosomal RNA expression as internal reference. Two independent assays were carried out and it was accepted a difference $<1.0$ between the threshold cycles. One sample was randomly chosen to be analyzed in all assays as a reference and a negative control was also used. For cDNA synthesis, $1 \mu \mathrm{g}$ of total RNA was reverse transcribed in a solution of $20 \mu \mathrm{l}$ containing $100 \mathrm{ng}$ of random hexamer primers, $20 \mu \mathrm{M}$ dNTPs mixture, $50 \mathrm{mM}$ Tris- $\mathrm{HCl}, 75 \mathrm{mM}$ $\mathrm{KCl}, 1.5 \mathrm{mM} \mathrm{MgCl} 2,5 \mathrm{mM}$ DTT and $100 \mathrm{U}$ SuperScript III reverse transcriptase (Invitrogen, Life Technologies, CA, USA) at $50^{\circ} \mathrm{C}$ for one hour and the reaction was terminated at $70^{\circ} \mathrm{C}$ for $15 \mathrm{~min}$.

For each qRT-PCR, 20 mM Tris- $\mathrm{HCl}$ (pH 8.4), $50 \mathrm{mM}$ $\mathrm{KCl}, 200 \mu \mathrm{M}$ each dNTP, 5\% dimethyl sulphoxide, $100 \mathrm{nM}$ sense and antisense oligonucleotides for each gene, $1.0 \mathrm{mM} \mathrm{MgCl}$, 1.5 times the volume of SYBR-Green, 1.5 U of Platinum Taq DNA Polymerase (Invitrogen), $100 \mathrm{ng}$ 
and $1 \mathrm{ng}$ of cDNA for ERCC1 and 18S determination, respectively, to a final volume of $20 \mu 1$, were used. After 40 cycles, the denaturation curves were obtained in the range of 72 to $95^{\circ} \mathrm{C}$. The oligonucleotides were designed with the Primer 3 software (http://frodo.wi.mit.edu/primer3/), version 0.4.0, and purchased from Integrated DNA Technologies Inc. (Coralville, IO, USA): ERCC1 sense 5'-GACTATGTGCTG GGCCAGAG-3', ERCC1 antisense 5'-GTAGCGGAGGCT GAGGAAC-3'; 18S sense 5'-CGCCGCTAGAGGTGAAAT TC-3', 18S antisense 5'-TTGGCAAATGCTTTCGCTC-3'. The product of the each qRT-PCR was analyzed with the Rotor-Gene 6 software, version 6.0 (Corbett Research, Sydney, Australia), and the relative expression ratio of ERCC1 was calculated as proposed by Pfaffl (24). The deviation of control minus sample of the target (ERCC1) or reference (18S) gene transcripts were calculated according to the derived cycle threshold values $\left(\mathrm{C}_{\mathrm{t}}\right)$. The optimal cut-off value for differentiation of the patient categories (high or low expression) was defined by ROC analysis (see below). The qRT-PCR efficiencies of ERCC1 and 18S transcripts were 2.1 and 1.99 , respectively.

Genotyping of the ERCC1 codon 118. The ERCC1 codon 118 SNP was detected by PCR-restriction fragment length polymorphism (RFLP). Genomic DNA (50 ng) was amplified in a 50- $\mu 1$ mixture of $200 \mu \mathrm{M}$ of each dNTP, $2.5 \mathrm{U}$ Taq DNA polymerase, $20 \mathrm{mM}$ Tris- $\mathrm{HCl}$ (pH 8.4), $50 \mathrm{mM} \mathrm{KCl}, 1.5 \mathrm{mM}$ $\mathrm{MgCl}_{2}$ and $0.2 \mu \mathrm{M}$ sense 5'-GCAGAGCTCACCTGAGGA AC-3' and $0.2 \mu \mathrm{M}$ antisense 5'-GAGGTGCAAGAAGAG GTGGA-3'. PCR products, after being digested by the BsrDI restriction enzyme (New England Biolabs, Beverly, MA, USA) at $60^{\circ} \mathrm{C}, 16 \mathrm{~h}$, were separated on $3 \%$ ethidium bromidestained agarose gel. The RFLP analysis of the resultant 208-bp fragment led to C/C (208 bp), C/T (208, 128 and $80 \mathrm{bp}$ ) and T/T (128 and $80 \mathrm{bp}$ ) genotypes. Gel images were obtained using the ImageMaster VDS (Amersham Biosciences AB, Uppsala, Sweden).

Statistical methods. Disease-free survival (DFS) was defined as the time from the end of radiation therapy to any type of progression (loco-regional or distant, or second primary tumor). Overall survival (OS) was defined as the time from the end of radiation therapy to death from any cause. KaplanMeier curves were calculated and compared using log-rank test. The end of follow-up was March 31, 2009. Patients who were alive or had not progressed at the last follow-up were censored at that time.

Univariate and multivariate stepwise procedure Cox regression analyses were used to assess the association between potential prognostic factors and survival. Factors with $p$-values $<0.1$ in univariate analysis were included in multivariate analysis. Exploratory analyses were performed using Fisher's exact test or $\chi^{2}$, where appropriate. Continuous variables were compared by t-test. Spearman's rank correlation coefficient was calculated to assess the relationship involving discrete variables. The optimal cut-off value for differentiation of the patient categories (positive or negative) was defined by ROC analysis with the best sensitivity and specificity for each evaluable variable. All statistical tests were two-sided with significance defined as $\mathrm{p}<0.05$. Analyses were performed
Table I. Patient characteristics.

No. of patients (\%)

\begin{tabular}{|c|c|}
\hline \multicolumn{2}{|l|}{ Gender } \\
\hline Male & $56(81)$ \\
\hline Female & $13(19)$ \\
\hline \multicolumn{2}{|l|}{ Age (years) } \\
\hline Median & 56 \\
\hline Range & $25-79$ \\
\hline \multicolumn{2}{|c|}{ Primary tumor site } \\
\hline Oral cavity & $28(41)$ \\
\hline Oropharynx & $8(12)$ \\
\hline Hypopharynx & $11(16)$ \\
\hline Larynx & $22(32)$ \\
\hline \multicolumn{2}{|l|}{ T stage } \\
\hline pT1-pT2 & $15(22)$ \\
\hline pT3-pT4 & $54(78)$ \\
\hline \multicolumn{2}{|l|}{$\mathrm{N}$ stage } \\
\hline pN0-pN1 & $29(42)$ \\
\hline pN2-pT3 & $40(58)$ \\
\hline \multicolumn{2}{|l|}{ Grade } \\
\hline 1 & $24(35)$ \\
\hline 2 & $36(52)$ \\
\hline 3 & $9(13)$ \\
\hline \multicolumn{2}{|c|}{ Resection-margin status } \\
\hline Positive & $18(26)$ \\
\hline Negative & $51(74)$ \\
\hline \multicolumn{2}{|l|}{ Positive nodes } \\
\hline $0-1$ & $26(38)$ \\
\hline 2 or more & $43(62)$ \\
\hline \multicolumn{2}{|c|}{ Extracapsular spread } \\
\hline Positive & $27(39)$ \\
\hline Negative & $42(61)$ \\
\hline
\end{tabular}

using the MedCalc software (MedCalc, Mariakerk, Belgium), version 9.3.2.0.

\section{Results}

Patient characteristics and clinical outcomes. Sixty-nine patients were identified from 1998 to 2007 (Table I). Median age was 56 years and $81 \%$ were male. Oral cavity was the most common primary site (41\%). Forty patients $(58 \%)$ were classified as high-risk and the remaining 29 patients (42\%) were classified as intermediate-risk (3). Extracapsular spread in positive lymph nodes was identified in 27 patients (39\%) and surgical margins were microscopically involved in 18 patients $(26 \%)$. The median time elapsed from surgery to adjuvant chemoradiation was 2.9 months (range, 1.3-10.6 months) and the median duration of radiation therapy was 


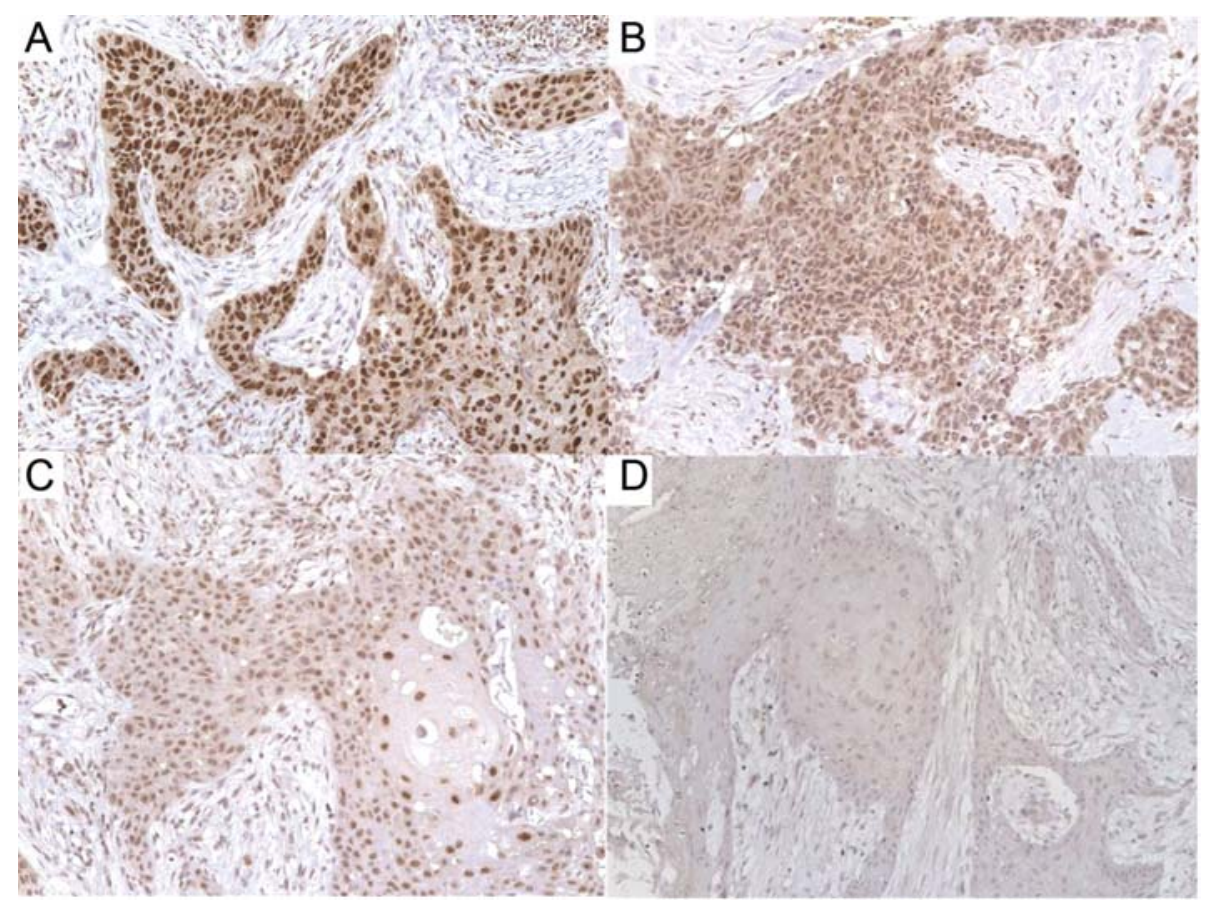

Figure 1. Immunohistochemistry representative images of ERCC1 tumor expression (x400). (A) H-score 3; (B) H-score 2; (C) H-score 1; (D) H-score 0 . Adjacent non-malignant cells were used as a reference (intensity grade, 2).

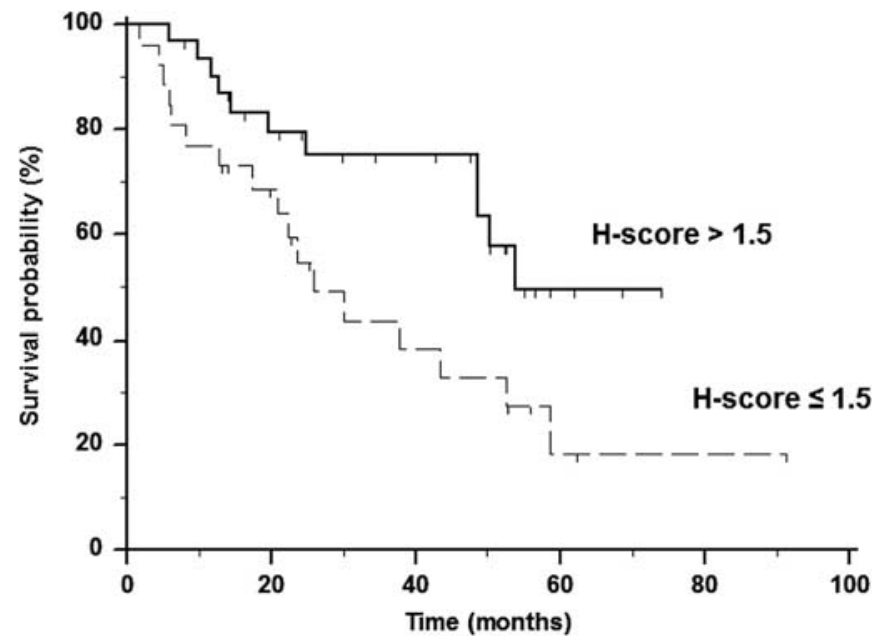

Figure 2. Kaplan-Meier overall survival curves according to ERCC1 $\mathrm{H}$-scores.

56 days (range, $37-134$ days). The median number of administered chemotherapy cycles was 3 , and the median overall treatment time (from surgery to the end of adjuvant chemoradiation) was 21 weeks (range, 13-54 weeks).

The median follow-up time for living patients was 47 months (range, 6-91 months), being 39 patients alive and 29 disease-free. Eleven loco-regional and 7 distant relapses were observed, 10 patients were diagnosed with a secondary primary tumor and 30 patients died, 22 as a consequence of disease progression. The 5 -year OS rate was $40 \%$ and the median OS was 52.5 months. The 5-year DFS rate was $31 \%$, and the median DFS was 36.6 months. No significant difference in OS was detected in terms of gender, stage, grading and pathological risk features.
Immunohistochemical analysis of ERCC1. The expression of ERCC 1 by immunohistochemistry was evaluated in 59 patients. Tissue blocks were not available for 10 patients. Representative examples of tumor expression of $\mathrm{H}$-scores are shown in Fig. 1. The median H-score was 2. The optimum cut-off value for discrimination of dead and living patients was calculated as 1.5 (sensitivity $61 \%$, specificity $68 \%$, area under the ROC curve $0.63,95 \%$ CI $0.49-0.75$, $\mathrm{p}=0.081$ ), and those 32 patients $(54 \%)$ whose tumors presented $\mathrm{H}$-score $>1.5$ were classified as having high $\mathrm{H}$-scores. These high $\mathrm{H}$-score patients presented better 5-year OS rate in comparison to those with low $\mathrm{H}$-scores (50\% vs. $18 \%$, HR $0.43,95 \%$ CI $0.20-0.90, p=0.026$ ), as shown in Fig. 2. Among patients classified as high-risk, no difference in terms of OS was observed, regarding $\mathrm{H}$-score: 48.7 months (high $\mathrm{H}$-score) vs. 23.5 months (low H-score; HR 0.56, 95\% CI 0.23-1.40, $\mathrm{p}=0.219$ ).

ERCC1 mRNA expression. ERCCI mRNA expression was determined in 45 patients. Tissue blocks were not available for 10 patients, isolated RNA was degraded in 10 patients and the small amount of isolated RNA was not possible to be analyzed in the four remaining patients. The deviation of $C_{t}$ $\left(\triangle \mathrm{C}_{\mathrm{t}}\right)$ of $E R C C l$ gene had mean value of $-3.05 \pm 3.10$, and $\Delta \mathrm{C}_{\mathrm{t}}$ of $18 \mathrm{~S}$ gene had mean value of $-4.59 \pm 4.09$. The median of relative ERCC1 mRNA expression was 2.58 (range, 0.25 19.26). The optimum cut-off value for discrimination of dead and living patients was calculated as 3.1 (sensitivity $89 \%$, specificity $48 \%$, area under the ROC curve $0.58,95 \%$ CI $0.43-0.73, \mathrm{p}=0.335)$, and those 15 patients $(33 \%)$ whose tumors presented normalized ERCC1 mRNA expression $>3.1$ were classified as having high expression. These patients with high ERCC1 mRNA expression presented better 5-year OS rate in comparison to those with low expression $(86 \%$ vs. $31 \%$, 


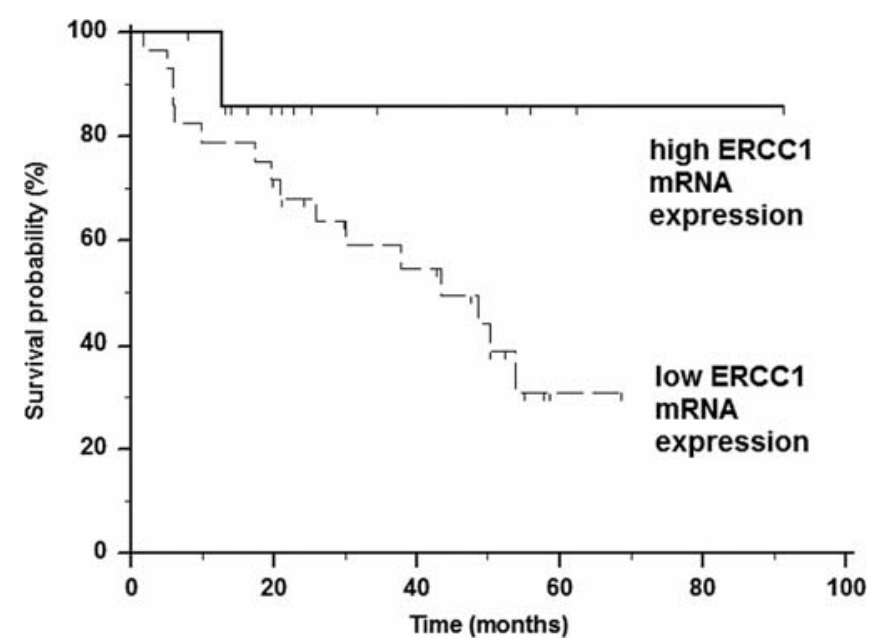

Figure 3. Kaplan-Meier overall survival curves according to ERCC1 mRNA relative expression.

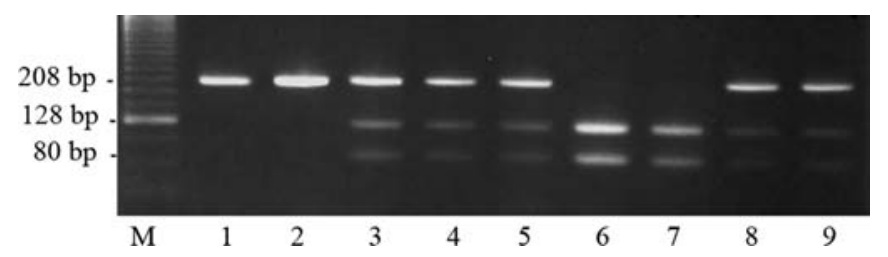

Figure 4. PCR products, after being digested with BsrDI, separated by electrophoresis on $3 \%$ ethidium bromide-stained agarose gel. The RFLP analysis of the resultant 208-bp fragment led to C/C (208 bp), C/T (208, 128 and $80 \mathrm{bp}$ ) and $\mathrm{T} / \mathrm{T}(128$ and $80 \mathrm{bp})$ genotypes. Lanes 1 and $2, \mathrm{C} / \mathrm{C}$ genotype; lanes 3-5, 8 and 9, C/T genotype; lanes 6 and 7, T/T genotype; lane M, 25 bp marker.

HR 0.26 , 95\% CI 0.14-1.01, p=0.052), as shown in Fig. 3. Among patients classified as high-risk, no difference in terms of overall survival was observed, regarding ERCC1 mRNA expression: not reached (high expression) vs. 30 months (low expression; HR 0.32, 95\% CI 0.12-1.29, $\mathrm{p}=0.121$ ).

The Spearman correlation between $\mathrm{H}$-score and ERCC1 mRNA expression in 44 patients revealed a rho coefficient of rank correlation of 0.073 (95\% CI-0.23-0.36, $\mathrm{p}=0.632) \cdot \chi^{2}$ of categorized data on ERCCl protein and mRNA expression was not significant $\left(\chi^{2}=0.000, p=0.988\right)$.

Using a Cox proportional hazards regression model multivariate analysis, H-score (>1.5 vs. $\leq 1.5$; adjusted HR 0.20 , 95\% CI 0.07-0.57, p=0.003) and normalized ERCC1 mRNA expression (>3.1 vs. $\leq 3.1$; adjusted HR 0.12 , 95\% CI 0.03 $0.59, \mathrm{p}=0.009$ ) remained significant as favorable prognostic factors after adjusting.

Genotyping of the ERCC1 codon 118. Genotyping of the ERCC1 codon 118 was performed in 49 patients, and the frequencies of $\mathrm{C} / \mathrm{C}, \mathrm{C} / \mathrm{T}$ and $\mathrm{T} / \mathrm{T}$ were 37,39 and $24 \%$, respectively. Representative genotyping results are shown in Fig. 4. Tissue blocks were not available for 10 patients, isolated DNA was degraded in 7 patients and in the 3 remaining patients, the small amount of isolated DNA was not possible to be analyzed. This polymorphism followed the HardyWeinberg's equilibrium among patients $\left(\chi^{2}=2.242, \mathrm{p}=0.326\right)$. ERCC1 mRNA expression was not different between patients presenting with the $\mathrm{C} / \mathrm{C}$, or $\mathrm{C} / \mathrm{T}$, $\mathrm{T} / \mathrm{T}$ genotypes $(\mathrm{p}=0.758$ ). No significant association was found between age, gender, stage, grading and pathological risk features and ERCC1 codon 118 genotypes. No difference was detected among $\mathrm{C} / \mathrm{C}, \mathrm{C} / \mathrm{T}$ and $\mathrm{T} / \mathrm{T}$ genotypes in terms of 5 -year OS rates $(45$, $46,46 \%$; $\mathrm{p}=0.808$ ).

\section{Discussion}

We studied the expression of ERCC1 at protein and mRNA levels, as well as the SNP T19007C of ERCC1 as prognostic markers in patients with high or intermediate risk HNSCC treated with surgery and adjuvant chemoradiation with cisplatin. We found that patients with high expression of ERCC1, either at the protein or mRNA levels, had better prognosis. In disagreement with our data, previous published data obtained in 96 HNSCC patients have shown worse OS in patients whose tumors were positive for ERCC1, as determined by immunohistochemistry, and treated with induction chemotherapy (cisplatin and 5-fluorouracil), followed by definitive radiotherapy in responding patients (8). A similar deleterious effect for high ERCC1 expression was shown in 45 HNSCC patients treated with cisplatin-based chemoradiation (25), and also among 34 HNSCC treated by induction chemotherapy (cisplatin and docetaxel) followed by concurrent cisplatinbased chemoradiation (26). More recently, two other studies have shown no influence on response rate or survival for ERCC1 expression in HNSSC patients treated by cisplatinbased induction chemotherapy, followed by radiation therapy or radical surgery, or concurrent cisplatin, radiotherapy and cetuximab $(27,28)$. On the other hand, studies done in two other tobacco-related cancers, namely non-small cell lung cancer and pancreatic adenocarcinoma, treated by surgery alone, indicate that ERCC1 positivity may implicate in a favorable prognosis, which is in line with our results $(13,14,29)$.

Thus, the prognostic value of ERCC1 may be dependent on the treatment modality. In surgically treated HNSCC patients, the high expression of ERCC1 would be associated with better prognosis and an opposite effect would be seen in those patients treated with (chemo-)radiation, preceded or no by induction chemotherapy. The underlying mechanisms could related to the dual nature of ERCC1, to favor less mutagenesis and be associated with less aggressive tumors or to counteract cisplatin induced cell death (30). This interpretation, as commented by Gazdar (15), is compatible with the results of a large biomarker study in non-small cell lung cancer (10). Increased ERCC1 expression was also shown to be correlated with improved outcome of patients treated with cisplatin as an adjuvant therapy for curatively resected gastric cancer (31). The clinical scenario of the latter study is analogous to ours, an aggressive tumor primarily treated by surgery, with a modest benefit for adjuvant therapy.

Two additional issues may confound the interpretation of studies addressing ERCC1 as a biomarker. First, the inconsistencies of ERCC1 expression as determined by $\mathrm{H}$-score in regard to prognosis, related to its subjective 
nature for quantification, inter- and intraobserver variability, and different cut-off values. Indeed, the accuracy of the antiERCC1 antibody here used may be another issue of concern (32). Second, since the relationship of ERCC1 mRNA level and protein expression may be variable, the method of ERCC1 detection may be critical. In this regard, we were reassured by our results, which showed that ERCC1 was prognostic both at mRNA and protein levels. An additional strength of our work was the demonstration of the feasibility of ERCC1 mRNA expression and SNP genotyping using archived formalin-fixed tissue and not frozen samples, which are not routinely available. In terms of biomarkers validation, an increasing number of studies are showing consistent results of quantification of target genes in formalin-fixed, paraffin-embedded archived tissues. Those successful determinations of mRNA expression are being achieved by using well developed extraction kits and methodologies (33).

The 5-year OS and DFS rates we observed (39 and 30\%, respectively) are inferior to those described in phase III trials $(2,3)$. Possible explanations are the small percentage of patients $(12 \%)$ with primary tumor located in the oropharynx, a high frequency of microscopically involved surgical margins (26\%), and above all, a very long median overall treatment time ( 21 weeks) from surgery to the end of chemoradiation.

Our results suggest that T19007C SNP in the ERCC1 gene does not influence OS in our patients, in contrast to others, which found an association with response to platinum-based chemotherapy and survival in esophageal cancer, colorectal cancer, ovarian cancer and non-small cell lung cancer patients (17,34-36). A proposed mechanism is that T19007C SNP may decrease ERCC1 mRNA stability and consequently, protein expression. In prostate cancer, however, considerable interindividual differences in ERCC1 mRNA expression was seen among 376 patients, which could only partially be attributed to genetic (SNP) variation but could also be modified by factors such as plasma levels of antioxidants (37). To evaluate several polymorphic variants related with a specific activity, such as DNA-repair, seems interesting in the individual level. As reported by Quintela-Fandino et al, the presence of polymorphic variants in DNA-repair genes are powerful prognostic factors and predictive of response to cisplatin in HNSCC patients (38).

We conclude that high immunohistochemical expression of ERCC1 protein and high ERCC1 mRNA expression seem to be associated with better prognosis in HNSCC patients submitted to surgery and adjuvant cisplatin-based chemoradiation. ERCC1 expression may be used to better stratify HNSCC patients in clinical trials evaluating adjuvant cisplatinbased chemoradiation, however, a prospective validation is necessary.

\section{Acknowledgements}

This study was presented in the 2010 Annual Meeting of the American Society of Clinical Oncology (ASCO), held in Chicago, 4-8 June 2010. The authors are indebted to Bruno Ferenc Papp Cadima for his assistance in qRT-PCR assays, and also to Aleylove Talans for editing assistance.

\section{References}

1. Kamangar F, Dores GM and Anderson WF: Patterns of cancer incidence, mortality, and prevalence across five continents: defining priorities to reduce cancer disparities in different geographic regions of the world. J Clin Oncol 24: 2137-2150, 2006.

2. Cooper JS, Pajak TF, Forastiere AA, et al: Prospective concurrent radiotherapy and chemotherapy for high-risk squamouscell carcinoma of the head and neck. N Engl J Med 350: 1937-1944, 2004

3. Bernier J, Domenge C, Ozsahin M, et al: Postoperative irradiation with or without concomitant chemotherapy for locally advanced head and neck cancer. N Engl J Med 350: 1945-1952, 2004

4. Fietkau R, Lautenschläger C, Sauer R, et al: Postoperative concurrent radiochemotherapy versus radiotherapy in high-risk SCCA of the head and neck: results of the German phase III trial ARO 96-3. J Clin Oncol 24 (Suppl. 18): 5507, 2006.

5. Bernier J, Cooper JS, Pajak TF, et al: Defining risk levels in locally advanced head and neck cancers: a comparative analysis of concurrent postoperative radiation plus chemotherapy trials of the EORTC (\#22931) and RTOG (\#9501). Head Neck 27: $843-850,2005$.

6. Rabik CA and Dolan ME: Molecular mechanisms of resistance and toxicity associated with platinating agents. Cancer Treat Rev 33: 9-23, 2007.

7. Niedernholfer LJ, Odijk H, Budzowska M, et al: The structurespecific endonuclease Ercc1-Xpf is required to resolve DNA interstrand cross-link-induced double-strand breaks. Mol Cell Biol 24: 5776-5787, 2004.

8. Handra-Luca A, Hernandez J, Mountzios G, et al: Excision repair cross complementation group 1 immunohistochemical expression predicts objective response and cancer-specific survival in patients treated by cisplatin-based induction chemotherapy for locally advanced head and neck squamous cell carcinoma. Clin Cancer Res 13: 3855-3859, 2007.

9. Warnecke-Eberz U, Metzger R, Miyazono F, et al: High specificity of quantitative excision repair cross-complementing 1 messenger RNA expression for prediction of minor histopathological response to neoadjuvant radiochemotherapy in esophageal cancer. Clin Cancer Res 10: 3794-3799, 2004.

10. Olaussen KA, Dunant A, Fouret $\mathrm{P}$, et al: DNA repair by ERCC1 in non-small-cell lung cancer and cisplatin-based adjuvant chemotherapy. N Engl J Med 355: 983-991, 2006.

11. Cobo M, Isla D, Massuti B, et al: Customizing cisplatin based on quantitative excision repair cross-complementing 1 mRNA expression: a phase III trial in non-small-cell lung cancer. J Clin Oncol 25: 2747-2754, 2007.

12. Selvakumaran M, Pisarcik DA, Bao R, Yeung AT and Hamilton TC: Enhanced cisplatin cytotoxicity by disturbing the nucleotide excision repair pathway in ovarian cancer cell lines. Cancer Res 63: 1311-1316, 2003.

13. Simon GR, Sharma S, Cantor A, Smith P and Bepler G: ERCC1 expression is a predictor of survival in resected patients with non-small cell lung cancer. Chest 127: 978-983, 2005.

14. Zheng Z, Chen T, Li X, Haura E, Sharma A and Bepler G: DNA synthesis and repair genes RRM1 and ERCC1 in lung cancer. N Engl J Med 356: 800-808, 2007.

15. Gazdar AF: DNA repair and survival in lung cancer, the two faces of Janus. N Engl J Med 356: 771-773, 2007.

16. Li XQ, Li J, Shi SB, Chen P, Yu LC and Bao QL: Expression of MRP1, BCRP, LRP and ERCC1 as prognostic factors in nonsmall cell lung cancer patients receiving postoperative cisplatinbased chemotherapy. Int J Biol Markers 24: 230-237, 2009.

17. Moreno V, Gemignani F, Landi S, et al: Polymorphisms in genes of nucleotide and base excision repair: risk and prognosis of colorectal cancer. Clin Cancer Res 12: 2101-2108, 2006.

18. Chang MHC, Tzeng CH, Chen PM, et al: ERCC1 codon 118 $\mathrm{C} \rightarrow \mathrm{T}$ polymorphism associated with ERCC1 expression and outcome of FOLFOX-4 treatment in Asian patients with metastatic colorectal carcinoma. Cancer Sci 100: 278-283, 2009.

19. Ryu JS, Hong YC, Han HS, et al: Association between polymorphisms of ERCC1 and XPD and survival in non-smallcell lung cancer patients treated with cisplatin combination chemotherapy. Lung Cancer 44: 311-316, 2004.

20. Carles J, Monzo M, Amat M, et al: Single-nucleotide polymorphisms in base excision repair, nucleotide excision repair, and double strand break genes as markers for response to radiotherapy in patients with Stage I to II head-and-neck cancer Int J Radiat Oncol Biol Phys 66: 1022-1030, 2006. 
21. Krivak TC, Darcy KM, Tian C, et al: Relationship between ERCC1 polymorphisms, disease progression, and survival in the Gynecologic Oncology Group phase III trial of intraperitoneal versus intravenous cisplatin and paclitaxel for stage III epithelial ovarian cancer. J Clin Oncol 26: 3598-3606, 2008.

22. Abboud O, Weng X, Guertin L, et al: ERCC1 polymorphism in patients with locally advanced head and neck squamous cell carcinoma treated with concomitant chemoradiation: prevalence and impact on treatment efficacy. J Clin Oncol 27(Pt I): 309s, 2009.

23. Al-Haddad S, Zhang Z, Levgue E, et al: Psoriasin (S100A7) expression and invasive breast cancer. Am J Pathol 155 : 2057-2066, 1999.

24. Pfaffl MW: A new mathematical model for relative quantification in real-time RT-PCR. Nucleic Acids Res 29: e45, 2001.

25. Jun HJ, Ahn MJ, Kim HS, et al: ERCC1 expression as a predictive marker of squamous cell carcinoma of the head and neck treated with cisplatin-based concurrent chemoradiation. Br J Cancer 99: 167-172, 2008

26. Fountzilas G, Bamias A, Kalogera-Fountzila A, et al: Induction chemotherapy with docetaxel and cisplatin followed by concomitant chemoradiotherapy in patients with inoperable nonnasopharyngeal carcinoma of the head and neck. Anticancer Res 29: 529-538, 2009

27. Koh Y, Kim TM, Jeon YK, et al: Class III B-tubulin, but not ERCC1, is a strong predictive and prognostic marker in locally advanced head and neck squamous cell carcinoma. Ann Oncol 20: 1414-1419, 2009.

28. Fountzilas G, Kalogera-Fountzila A, Lambaki S, et al: MMP9 but not EGFR, MET, ERCC1, P16, and P-53 is associated with response to concomitant radiotherapy, cetuximab, and weekly cisplatin in patients with locally advanced head and neck cancer. J Oncol 2009: 305908, 2009.

29. Akita H, Zheng Z, Takeda Y, et al: Significance of RRM1 and ERCC1 expression in resectable pancreatic adenocarcinoma. Oncogene 28: 2903-2909, 2009.
30. Yang J, Liu X, Niu P, et al: Dynamic changes of XPA, XPC, $\mathrm{XPF}, \mathrm{XPG}$ and ERCC1 protein expression and their correlation with levels of DNA damage in human bronchial epithelia cells exposed to benzo[a]pyrene. Toxicol Lett 174: 10-17, 2007.

31. Baek SK, Kim SY, Lee JJ, Kim YM, Yoon HJ and Cho KS: Increased ERCC1 expression correlates with improved outcome of patients treated with cisplatin as an adjuvant therapy for curatively resected gastric cancer. Cancer Res Treat 38: 19-24, 2006.

32. Bhagwat NR, Roginskaya VY, Acquafondata MB, Dhir R, Wood RD and Niedernhofer LJ: Immunodetection of DNA repair endonuclease ERCC1-XPF in human tissue. Cancer Res 69: 6831-6838, 2009.

33. Kwon MJ, Oh E, Lee S, et al: Identification of novel reference genes using multiplatform expression data and their validation for quantitative gene expression analysis. PLoS One 4: e6162, 2009.

34. Warnecke-Eberz U, Vallböhmer D, Alakus H, et al: ERCC1 and XRCC1 gene polymorphisms predict response to neoadjuvant radiochemotherapy in esophageal cancer. J Gastrointest Surg 13: 1411-1421, 2009.

35. Smith S, Su D, Rigault de la Longrais IA, et al: ERCC1 genotype and phenotype in epithelial ovarian cancer identify patients likely to benefit from paclitaxel treatment in addition to platinum-based chemotherapy. J Clin Oncol 25: 5172-5179, 2007.

36. Isla D, Sarries C, Rosell R, et al: Single nucleotide polymorphisms and outcome in docetaxel-cisplatin-treated advanced non-small-cell lung cancer. Ann Oncol 15: 1194-1203, 2004.

37. Woelfelschneider A, Popanda O, Lilla C, et al: A distinct ERCC1 haplotype is associated with mRNA expression levels in prostate cancer patients. Carcinogenesis 29: 1758-1764, 2008.

38. Quintela-Fandino M, Hitt R, Medina PP, et al: DNA-repair gene polymorphisms predict favorable clinical outcome among patients with advanced squamous cell carcinoma of the head and neck treated with cisplatin-based induction chemotherapy. J Clin Oncol 24: 4333-4339, 2006. 